\title{
Expansión metropolitana y movilidad: el caso de Caracas
}

\author{
Carmen Lizarraga. Universidad de Granada, Granada, España.
}

RESUMEN | El modo de expansión urbana del Área Metropolitana de Caracas (AMC) ha resultado en una fuerte segregación residencial según los ingresos y, paralelamente, en condiciones inequitativas de movilidad y accesibilidad. La desregulación y privatización del transporte colectivo dio lugar a un sector desorganizado y desarticulado. Las fuertes inversiones en infraestructuras de transporte público en las últimas décadas, como Metro o Metrocable, no han tenido los efectos esperados para reducir los graves impactos negativos (costos externos) del modelo (accidentalidad, congestión de tráfico, contaminación atmosférica y acústica), ni la exclusión social. En este artículo se estudian las características del modelo de movilidad del AMC en el contexto metropolitano latinoamericano, y los efectos indeseados que provoca, mediante las últimas aportaciones teóricas y datos estadísticos disponibles. Se concluye exponiendo algunas propuestas para avanzar hacia la movilidad urbana sostenible.

PALABRAS CLAVE | áreas metropolitanas, fragmentación urbana, movilidad, transporte urbano.

ABSTRACT | The mode of urban expansion in Caracas Metropolitan Area (CMA) has caused high levels of residential segregation and, at the same time, unequal conditions related to urban mobility and accessibility. Deregulation and privatization of the collective transport induced the emergence of a disorganized and disarticulated sector. The big investments in public transport infrastructures, such as the subway or Metrocable, did not have the expected effects to reduce the social exclusion or the negative impacts of the model (traffic congestion, accidents, pollution). In this work we will analyze the mobility model combined with the expansion model of the CMA, through the study of the features of the mobility model and its undesired effects within the Latin-American context. We will use the available statistical data and the last theoretical contributions. Finally, we will put forward some proposals to achieve sustainable urban mobility.

KEY WORDS | metropolitan areas, urban fragmentation, mobility, urban transportation.

Recibido el 25 de septiembre de 2010, aprobado el 13 de julio de 2011.

E-mail: clizarra@ugr.es. 


\section{Introducción}

La movilidad urbana, entendida como el desplazamiento de las mercancías o de las personas entre distintos puntos de una ciudad, va ligada a la accesibilidad de los individuos a bienes, servicios, actividades y destinos que les permiten obtener ingresos o satisfacer sus necesidades. En las últimas décadas se ha producido un aumento de la movilidad que se ha resuelto con la sobreutilización de los modos motorizados, en especial del automóvil. El espacio público está tomado por los coches privados, la calle tradicional se convierte en vía de circulación y su uso longitudinal es prioritario respecto del transversal. Las grandes ciudades y metrópolis modernas comparten problemas relativos a los accidentes de tránsito, la congestión vehicular, la contaminación atmosférica y acústica, junto con las desigualdades sociales derivadas de este modelo. En torno a estos graves hechos ha surgido una literatura económica, no exenta de crítica, cuyo objetivo es cuantificar los costos externos del transporte. Al mismo tiempo, los aspectos relativos a la sostenibilidad, la accesibilidad y la exclusión social se han incorporado a los estudios científicos de movilidad. En la política local, la movilidad urbana sostenible se ha convertido en uno de los pilares de la mejora de la calidad de vida.

En América Latina, los problemas de movilidad (accidentalidad vial, congestión de tránsito, inseguridad, polución...) están relacionados con el progresivo incremento del uso del transporte privado y el correspondiente decremento del colectivo, y se distribuyen de forma inequitativa según características sociales o individuales. Este trabajo traslada la discusión teórica sobre movilidad sustentable a la realidad latinoamericana, en general, y a la caraqueña, en particular. Se exponen las características del modelo de expansión metropolitana y movilidad en el Área Metropolitana de Caracas (AMC), así como los problemas y retos a que se enfrenta. En primer lugar, se revisan las aportaciones teóricas más recientes que relacionan movilidad, accesibilidad y exclusión social. En segundo lugar, se analiza la disponibilidad de infraestructuras para la movilidad metropolitana. En tercer lugar, se estudia el modelo de movilidad del AMC y el consumo de recursos asociado, en comparación con el modelo metropolitano latinoamericano, a partir de los datos ofrecidos por el Observatorio de Movilidad Urbana (OMU) de América Latina sobre las quince mayores metrópolis de la región (Corporación Andina de Fomento [CAF], 2010). En cuarto lugar, se especifican los impactos negativos que provoca este modelo, como accidentalidad, congestión del tráfico o contaminación atmosférica, y las medidas adoptadas en esta materia por las instituciones. Se concluye exponiendo los retos que debe asumir el AMC, si desea contribuir a mejorar las condiciones de vida de sus habitantes.

\section{Aspectos teóricos y metodológicos}

\section{Movilidad y accesibilidad}

La movilidad es una variable cuantitativa (número de viajes/día, pasajeros $/ \mathrm{km}$ / día, tiempo medio del viaje...) que mide la cantidad de desplazamientos que las 
personas o mercancías realizan en un determinado sistema o ámbito socioeconómico, e incluye el espacio y tiempo en que se producen los desplazamientos, los motivos que los originan o el modo utilizado. El sistema de transporte proporciona la infraestructura, los vehículos, los operadores y los servicios y normas de circulación necesarios para que los individuos se desplacen. Hasta finales de la década de los 70 del siglo pasado, la movilidad se asociaba a la provisión de servicios de transporte, y la planificación priorizaba el transporte privado y por carretera, en lugar de los modos públicos colectivos (Da Silva, Da Silva Costa \& Macedo, 2008). Los severos y crecientes problemas de seguridad, congestión vial o contaminación medioambiental que afectan a las ciudades han provocado un cambio en la concepción y planificación de la movilidad urbana. Junto con el acceso de los individuos a los modos de transporte, la nueva concepción de movilidad incluye el ingreso, el género, la edad, la ocupación o el nivel educacional como factores que la explican (Vasconcellos, 2010a).

La creciente preocupación por el deterioro medioambiental, el uso racional de los recursos y la calidad de vida, se tradujo en los años 90 en la incorporación del concepto de desarrollo sostenible ${ }^{1}$ a la agenda política y económica de instituciones y organismos supranacionales. Como consecuencia, los estudios y las políticas de movilidad están añadiendo a sus objetivos la sostenibilidad, la accesibilidad o la inclusión social (Estevan \& Sanz, 1996; Miralles, 2002). Un modelo de movilidad urbana sostenible depende de la existencia de un sistema y de unos patrones de transporte que permitan la accesibilidad a medios y oportunidades para cubrir las necesidades económicas, medioambientales y sociales, aminorando las externalidades negativas asociadas (European Commission, 2001). A pesar de que los principios en que se basa la movilidad urbana sostenible están extendidos internacionalmente, su planificación exige la adaptación a cada contexto específico, según sean sus prioridades y características (Da Silva et al., 2008). En América Latina, la aplicación de estrategias y políticas de movilidad urbana sostenible debe tomar como punto de partida los altos niveles de desigualdad, informalidad y baja calidad espacial de sus ciudades. En este contexto, las necesidades de movilidad urbana sostenible se refieren a la consideración del espacio vial como espacio democrático y seguro; al control de la dispersión urbana y del uso de energía; a la reducción de la degradación ambiental; y al aumento de la accesibilidad para los pobres y, en general, de la eficiencia de la ciudad (Vasconcellos, 2010b). Desde esta perspectiva, las políticas de movilidad urbana sostenible no tienen por qué ser únicamente políticas de transporte y la sostenibilidad ha de entenderse como un objetivo global y articulado (Gudmundsson \& Höjer, 1996).

El objetivo de las políticas de movilidad es mejorar la accesibilidad de los ciudadanos, definida, a finales de la década de los 50 del siglo pasado, en términos de oportunidades potenciales para la interacción (Hansen, 1959). A partir de los años

1 Un sistema es sostenible si el uso de recursos renovables no supera sus tasas de regeneración o el tiempo de obtención de sustitutos, y si las emisiones de contaminación tampoco superan la capacidad de asimilación del medioambiente (Daly, 1990). 
90, siguiendo a Sen (1999), se reformuló el concepto de accesibilidad de manera más amplia, incorporándolo como meta política y ahora referido a la ordenación del territorio o a la mayor seguridad en las calles, ya no circunscrito al transporte. Se entendía que las limitaciones del desarrollo no se derivaban de la falta de alimentos o de oportunidades, sino de la falta de acceso a los mismos. De este modo, se relaciona la accesibilidad con la facilidad para llegar a los bienes, servicios, actividades y destinos que, en conjunto, se denominan oportunidades (Litman, 2010). En este sentido, la accesibilidad se puede valorar según el costo o dificultad de desplazamiento para cubrir la necesidad, y tiene una doble dimensión: territorial e individual. Esto redunda en que su distribución entre los ciudadanos sea heterogénea, condicionada tanto por el ámbito espacial como por el nivel de ingresos, el género o la edad (Sanz, 2010).

En numerosas ciudades latinoamericanas, la falta de acceso es un factor de exclusión social que afecta en mayor medida a los colectivos de la periferia, ya que los incapacita para alcanzar las oportunidades que les permitan romper el círculo vicioso de la pobreza. Mayores índices de movilidad no llevan aparejados, necesariamente, mayores índices de accesibilidad, que se pueden lograr creando cercanía. Tampoco existe una relación biunívoca entre mejora de accesibilidad e inversión en autopistas urbanas, que solo serán utilizadas por usuarios de vehículos privados motorizados y, en mayor medida, por los de ingresos más altos. Esta relación directa obvia las necesidades sociales de transporte y, trasladada a la política, genera inequidad en la distribución del espacio y soslaya la dimensión individual y temporal de la accesibilidad. Sus impactos negativos se amplifican en territorios con altos índices de desigualdad, como lo son muchos en América Latina (Miralles \& Cebollada, 2003; Vasconcellos, 2005, 2010a).

\section{Movilidad y exclusión social}

La movilidad de los ciudadanos asociada al uso del automóvil ha crecido un $40 \%$ en la segunda mitad del siglo veinte, y esta dependencia ha generado desigualdades en los niveles de accesibilidad según edad, género, ingresos u otras características personales y sociales. La posesión de un vehículo motorizado es un elemento clave del nivel de accesibilidad, al tiempo que no poseerlo se convierte en un factor de exclusión social (Rodrigue, Comtois \& Slack, 2006). La exclusión social implica la negación del acceso - a un individuo o grupo - a las oportunidades de participar en la vida social y política de la comunidad (Kenyon, Lyons \& Rafferty, 2002). De esta forma, accesibilidad, exclusión social, movilidad y transporte están estrechamente vinculados, ya que desplazarse es una necesidad básica: permite el acceso a bienes, servicios y oportunidades y la creación de redes sociales, y puede ser considerada una de las libertades de las sociedades democráticas (Hine \& Mitchell, 2001; Cass, Shove \& Urry, 2005; Preston \& Rajé, 2007; Lazo, 2008). Deben, así, ir unidas las medidas de accesibilidad destinadas a planificar entornos urbanos donde se reduzcan los desplazamientos a largas distancias, y las de movilidad centradas 
en la mejora de las infraestructuras para los modos colectivos y no motorizados de transporte (Lizarraga, 2006a). En América Latina, la falta de coordinación e integralidad de las políticas de movilidad urbana ha impedido la articulación de las distintas iniciativas públicas y privadas y afectado negativamente la sustentabilidad (Naciones Unidas, 2010).

\section{Aspectos metodológicos}

La metodología tradicional de carácter técnico y exclusivamente cuantitativo supone que la movilidad es un proceso social natural, que sigue tendencias inalterables políticamente. El análisis económico neoclásico considera que la toma de decisiones sobre la demanda de transporte privado se realiza teniendo en cuenta el costo privado de su uso y no el costo marginal social, que incluye los costos externos o externalidades negativas: costos impuestos a terceros, no reflejados en el precio de mercado, como los accidentes viales o los efectos negativos de la congestión del tráfico urbano. Aunque existen numerosos trabajos y metodologías de medición de los costos externos (Maddison et al., 1996; Zegras, 1998; INFRAS/IWW, 1999, 2004; Nash, 2003) y las políticas de internalización han recibido el apoyo institucional de la Unión Europea, esta concepción de los impactos negativos del transporte no está exenta de críticas, principalmente porque prescinde del territorio y del tejido social en el que se producen los desplazamientos (Sanz, 2010). En este trabajo se asume la propuesta metodológica de Vasconcellos $(2005,2010 \mathrm{a})$ y se añaden aspectos socioeconómicos y ambientales al análisis de la movilidad urbana. Esta metodología permite clarificar cómo se generan los impactos negativos del modelo de movilidad y considerar aspectos sociales que van más allá de la monetización de los impactos.

A fin de contextualizar el modelo de movilidad analizado en la región latinoamericana se han utilizado diversas fuentes internacionales, nacionales y locales. El OMU suministra información cuantitativa sobre las quince principales áreas metropolitanas de la región (Buenos Aires, Belo Horizonte, Curitiba, Porto Alegre, Río de Janeiro, São Paulo, Santiago, Bogotá, San José, Ciudad de México, Guadalajara, León, Lima, Montevideo y Caracas). Estos datos han permitido comparar indicadores clave de movilidad del AMC con la zona de estudio del OMU. Además, se ha calculado un índice de la importancia porcentual de los recursos aplicados a la movilidad por modos motorizados sobre el peso de los desplazamientos en dichos modos $\left(\mathrm{I}_{\mathrm{r} / \mathrm{d}}^{\mathrm{j}}\right)$. Si es superior a 100, indica que el modo i está efectuando una sobreutilización del recurso $\mathrm{j}$.

$$
I_{r / d}^{j}=\frac{R^{j} \sum_{i} R_{i} R_{i}^{j}}{D_{i} \sum_{i} D_{i}}
$$


Siendo,

$\mathrm{D}_{\mathrm{i}}=$ Número de desplazamientos en el modo $\mathrm{i} ; \mathrm{i}=$ transporte individual motorizado, transporte colectivo.

$R_{i}^{j}=$ Cantidad de recurso $j$ empleado en el modo $i ; j=$ tiempo, espacio, costo, energía.

\section{Desarrollo urbano y movilidad en América Latina}

Los procesos de suburbanización y de metropolización, característicos del crecimiento de las ciudades desde la segunda mitad del siglo veinte, han provocado un aumento en los índices de movilidad urbana motorizada y en el consumo energético asociado (Unión Internacional de Transporte Público [UITP], 2005). El primero de estos fenómenos se caracteriza por el movimiento poblacional del centro a la periferia por diversos motivos, y se ha visto favorecido por el desarrollo de los medios de transporte (Clout, 1974). El segundo se refiere al incremento del área suburbana, en un proceso de expansión que desborda los límites urbanos y provoca una concentración poblacional en las periferias y un cambio en la especialización funcional de la urbe (Precedo, 1996). En los últimos años, el crecimiento de las ciudades sigue una tendencia radicalmente opuesta al objetivo de movilidad urbana sostenible; prueba de ello es que la población urbana de América Latina ha pasado del 56,4\% del total en 1970 al 79,5\% en 2010, y se espera que esta proporción siga aumentando (Comisión Económica para América Latina y el Caribe [CEPAL], 2009; CAF, 2010]. Las grandes metrópolis presentan una estructura urbana incompatible con la senda de rápido incremento del índice de motorización; una demanda de transporte que supera los límites de la oferta; un alto porcentaje de participación del transporte colectivo en la distribución por modos, junto a un deseo intenso de poseer un vehículo privado; y un mantenimiento deficiente de calles y espacio vial (Vasconcellos, 1996; Gakenheimer, 1999).

Venezuela, con una población urbana que asciende a un 93,6\% del total, se ha convertido en uno de los países más urbanizados de América Latina, junto con Argentina y Uruguay. La densidad poblacional de Caracas (4.041 hab. $/ \mathrm{km}^{2}$ ) es muy elevada, mayor que la de las grandes ciudades de Europa, muy superior a la densidad media de las metrópolis estudiadas por el OMU $\left(1.747 \mathrm{hab} . / \mathrm{km}^{2}\right)$ y solo superada por Bogotá. En las primeras décadas del siglo veinte comenzó un proceso de creación de urbanizaciones exclusivas, siguiendo el modelo desarrollado en Estados Unidos, que condujo a la expansión de la zona este de Caracas (Rebotier, 2009). Desde 1950, la ciudad se convirtió en un centro de atracción para las áreas rurales del país y para inmigrantes extranjeros, proceso que se acentuó con el boom petrolero de los años 60 y 70 . El rápido y desordenado aumento demográfico derivó en la aparición y expansión de asentamientos no planificados, sin infraestructuras públicas adecuadas, donde habita la población más pobre (UITP, 2003a; Metzner $\&$ Verma, 2008). Al mismo tiempo, se fueron creando áreas residenciales exclusivas 
donde se localizan la mayor parte de las actividades urbanas, pequeñas industrias y centros comerciales. La irregular topografía del área dificulta la conexión de algunos vecindarios y limita su desarrollo urbano (Figura 1).

En cuanto al Distrito Metropolitano de Caracas, unidad político-territorial de la ciudad, se creó en el año 2000 por ley especial derivada de la Constitución de 1999 y comprende los cinco municipios del Valle de Caracas: Libertador, Chacao, Sucre, Baruta y El Hatillo, estos cuatro últimos en el Estado Miranda. A fin de coordinar el funcionamiento del área, la Alcaldía Metropolitana de Caracas o Alcaldía Mayor asumió competencias del distrito en materia de planificación y ordenación urbanística, ambiental, arquitectura civil y viviendas de interés social; y también en lo relativo a vialidad urbana, circulación y ordenación del tránsito de vehículos y de servicios de transporte urbano intermunicipal de pasajeros (artículo 19 de la Ley especial sobre el régimen del distrito metropolitano de Caracas) (Asamblea Nacional Constituyente, 2000). Sin embargo, hasta ahora no se ha logrado la coordinación necesaria de las competencias entre los distintos niveles de gobierno (Barrios, 2001; Paiva, 2001). El distrito alberga una población aproximada de 3.200 .000 habitantes, a la que se suma una población flotante de alrededor de un millón de individuos, que trabajan en la ciudad aunque residen en ciudades satélites. La segmentación residencial según niveles de ingreso es muy alta. La mayor parte de la población del noreste y este vive en barrios populares; en el sureste se concentran los individuos con ingresos medio-altos, y en el eje central, los de ingresos medios y bajos. En el resto de las áreas no predomina un estrato social específico (Flórez, 1999). En Chacao se concentran urbanizaciones exclusivas de individuos de altos ingresos. En cuanto a la distribución espacial de la población, el distrito capital concentra el 66\% y el de Sucre agrupa la quinta parte (Cuadro 1).

CUADRo 1 | Distribución de la población en el AMC (porcentajes)

\begin{tabular}{l|r|r|r|r|r}
\hline ENTIDAD & 1990 & 2001 & 2005 & 2010 & 2015 \\
\hline & & & & & \\
DISTRITO CAPITAL & 67,88 & 66,47 & 66,04 & 65,31 & 64,90 \\
Municipio Libertador & 67,88 & 66,47 & 66,04 & 65,31 & 64,90 \\
ESTADO MIRANDA & 32,12 & 33,53 & 33,96 & 34,69 & 35,10 \\
Municipio Baruta & 9,27 & 9,44 & 9,62 & 9,89 & 10,07 \\
Municipio Chacao & 2,49 & 2,34 & 2,26 & 2,22 & 2,15 \\
Municipio El Hatillo & 1,71 & 1,96 & 2,07 & 2,20 & 2,31 \\
Municipio Sucre & 18,65 & 19,79 & 20,01 & 20,39 & 20,57 \\
& & & & & 3.285 \\
AMC (Millones de habitantes) & 2.686 & 2.763 & 3.140 & 3.221 & 10,59 \\
\hline
\end{tabular}

Fuente Instituto Nacional de Estadística (INE). Los datos de 1990 y 2001 CORRESPonden a los Censos DE POBLACIÓN, LOS DEMÁS SON PROYECCIONES DEL INE. 
FIGURA 1 | Área Metropolitana de Caracas, 2010

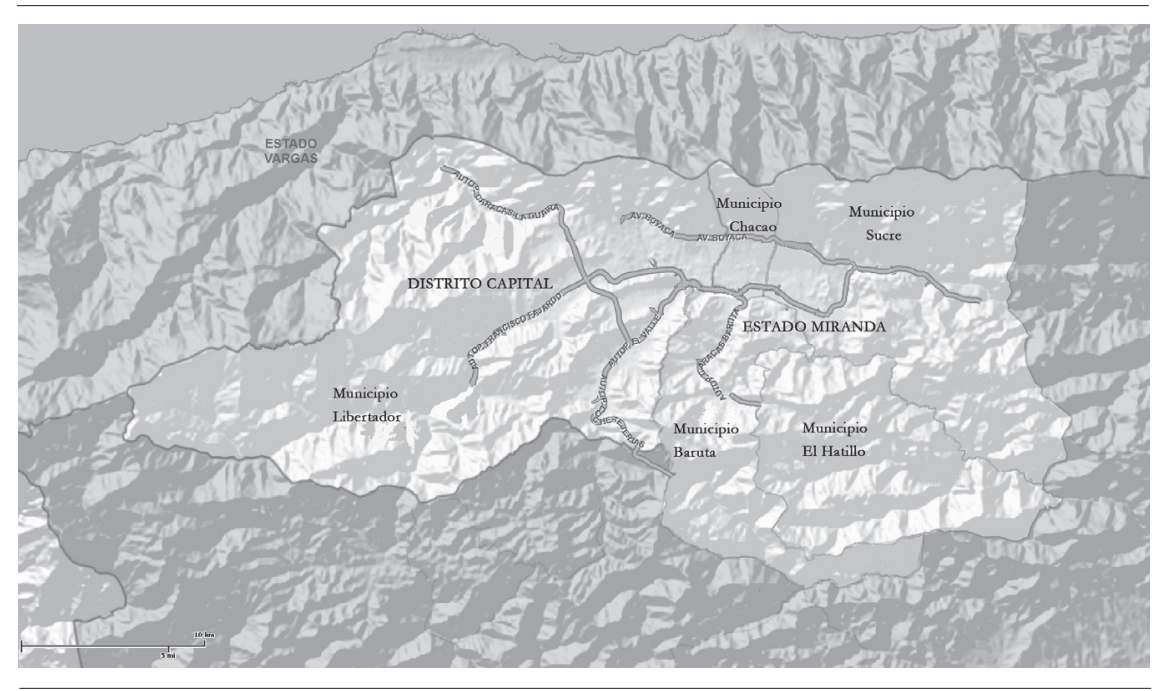

fuente Gerencia de Sistema de Información Geográfica Metropolitano, 2009.

La región metropolitana de Caracas suma más de cinco millones de habitantes e incluye el AMC, los Valles del Tuy Medio, la conurbación Guarenas-GuatireAraira, los Altos Mirandinos y el Litoral Central. Mediante un proceso de suburbanización, el AMC ha ido perdiendo su dinamismo poblacional frente a las subregiones periféricas, especialmente los Valles del Tuy, que se han convertido en un área residencial de los sectores medios, empobrecidos o vulnerables, debido al menor precio de la vivienda. El empleo de toda la región se concentra en el centro metropolitano; de ahí que el avance hacia la movilidad urbana sostenible sea un tema prioritario (Cariola \& Lacabana, 2003).

$\mathrm{El}$ insostenible modelo urbano generado provoca un aumento de los índices de movilidad, una reducción de la accesibilidad y un incremento de la exclusión social. La accesibilidad se reduce de forma general, puesto que todos, con independencia del ingreso, se beneficiarían de una mayor oferta y de más calidad de servicios públicos. Pero quienes sienten más agudamente los efectos negativos del modelo son los habitantes de las áreas periféricas, dada la situación del sistema vial de estas zonas, la baja calidad del transporte público que opera en ellas o la carencia de servicios públicos de salud o educación (Vasconcellos, 2010a). La disparidad inicial, económica, se transforma en marginalidad para unos, debido a la falta de seguridad, de equipamientos públicos o de espacios urbanos que permitan un tránsito peatonal seguro; y para otros, en dependencia de transportes individuales motorizados (Clichevsky, 2000; Giraldo, García, Ferrari \& Bateman, 2009).

\section{Infraestructura para la movilidad}

Las quince áreas metropolitanas objeto de estudio del OMU cuentan con una infraestructura para la movilidad que incluye un sistema vial $(245.000 \mathrm{~km})$ amplio, 
pero de baja calidad, y 32.600 intersecciones con semáforos. Esta infraestructura se completa con una escasa dotación de preferencias de circulación para transporte colectivo $(904 \mathrm{~km})$, ciclistas $(996 \mathrm{~km})$ y peatones $(50 \mathrm{~km})$. La longitud del sistema vial del AMC es de $2.758 \mathrm{~km}$ con 496 intersecciones semafóricas. Caracas, con San José, Montevideo y Guadalajara, no posee ningún kilómetro de vías con prioridad para el transporte público, y su infraestructura preferencial para peatones $(2,2 \mathrm{~km})$ y ciclistas $(14,4 \mathrm{~km})$ es muy baja, pese a su alta densidad poblacional. Los primeros planes de carreteras en Caracas fueron desarrollados en los años 40 del siglo pasado por consultores extranjeros y dieron lugar a una red de autopistas que mejoró la accesibilidad de los usuarios de automóviles, en detrimento de los usuarios de transporte colectivo (González-Casas, 1999).

La oferta de servicios de transporte colectivo es muy diversa y con un alto grado de informalidad. Coexisten operadores públicos y privados y flotas de autobuses muy heterogéneas y de dispar antigüedad (Vasconcellos, 2005; Naciones Unidas, 2010). La edad promedio de los vehículos de transporte colectivo en Caracas es dieciséis años en el caso del autobús estándar, y veinte años en el caso de los jeeps, frente a cinco años de los vehículos privados. Con estas cifras, se puede deducir que los usuarios del transporte colectivo sufren mayores niveles de inseguridad e incomodidad (CAF, 2010). Además, los vehículos de menor tamaño son más ventajosos para los operadores, lo que provoca más congestión del tránsito, contaminación y consumo del espacio vial (Figueroa, 2007).

El sistema de transporte colectivo del AMC está compuesto por el transporte masivo subterráneo (Metro), el recientemente creado Metrocable, y el subsistema superficial. Caracas inauguró el primer tramo del Metro en 1983 y su puesta en funcionamiento atrajo a individuos de ingresos altos (Flórez, 1999). Es uno de los sistemas más modernos de América y una opción que va ganando peso desde entonces. Operado por la compañía C.A. Metro de Caracas, cubre la zona central de la ciudad y se extiende a Los Teques. En un día medio laboral viaja más de un millón y medio de personas que se reparten entre las cuatro líneas existentes (Cuadro 2), con una frecuencia que bascula entre uno y diez minutos y una velocidad promedio de $80 \mathrm{~km} / \mathrm{h}$.

Además del Metro, existe un sistema de trenes del Instituto Autónomo Ferrocarriles del Estado (IAFE) que conecta Caracas con Tuy Medio mediante la línea 3 de Metro. El metro Los Teques es una nueva línea extraurbana inaugurada en noviembre de 2006 que transporta 37.000 pasajeros diarios, aproximadamente (Cuadro 2). Está en marcha el proyecto de extensión de las líneas 3 y 4 y se planea la construcción de la línea 5 y de un sistema hacia las poblaciones de Guarenas y Guatire (futura línea 6). El Metro articula la ciudad con su entorno y el área de influencia de la capital, disminuye los tiempos de viaje, emite $\mathrm{CO}_{2}$ en una proporción cincuenta veces inferior a la del vehículo privado, es más seguro y limita los niveles de congestión de tráfico, ya que tiene la capacidad de doscientos coches y tres autobuses. Su contribución al cambio climático se circunscribe a las consecuencias de la producción de electricidad (UITP, 2003b). Como contrapartida, los problemas a que se enfrenta incluyen la actual saturación de la línea 1 y la falta de integración con las 
unidades "por puesto" - minibuses que tienen entre 18 y 32 asientos ${ }^{2}$ - utilizadas en la mitad de los desplazamientos.

CUADRO 2 | Número de viajeros promedio en Metro, Metrobús y metro Los Teques en un día laboral

\begin{tabular}{|c|c|c|c|c|c|c|c|}
\hline & LÍNEA I & LÍNEA 2 & LÍNEA 3 & LÍNEA 4 & TOTAL METRO & METROBÚS & $\begin{array}{c}\text { METRO LOS } \\
\text { TEQUES }\end{array}$ \\
\hline 1983 & 183.834 & - & - & - & 183.834 & - & - \\
\hline 1990 & 779.288 & 136.617 & - & - & 915.905 & 49.372 & - \\
\hline 2000 & 703.029 & 127.517 & 63.816 & - & 894.362 & 74.177 & - \\
\hline 2005 & 976.198 & 197.329 & 88.846 & - & 1.262 .273 & 80.925 & - \\
\hline 2008 & 1.196 .604 & 252.510 & 132.434 & 41.668 & 1.623 .216 & 78.662 & 37.283 \\
\hline
\end{tabular}

fuente Gerencia Ejecutiva de Transporte Metro, 2009.

El Metro se complementa con una red de autobuses, con los cuales conforma el sistema Metro-Metrobús desde 1987. Este sistema, aunque no cubre toda el AMC, conecta las estaciones de Metro con otras zonas de la metrópoli y áreas limítrofes, y cuenta con diferentes horarios y un sistema de boleto integrado para ambos modos. Dispone de una infraestructura de servicios y modernos vehículos con mecanismos de seguridad interna que solo se detienen en las paradas preestablecidas.

El transporte público colectivo, más allá de la conexión territorial, es un instrumento de inclusión social. Una de sus funciones sociales es conectar los barrios más pobres con las zonas en que se concentran los servicios educativos o sanitarios y la oferta de empleo. Esto es de suma importancia, puesto que el 32\% de la población urbana venezolana vive en barrios situados en el extrarradio y débilmente conectados con el área central (Banco Mundial, 2002; UITP, 2007; United Nations-Habitat, 2008). Fue así que para paliar la falta de acceso de estos sectores, en el año 2006 se proyectó la construcción de una red de ocho ramales de teleféricos que conectan los barrios del AMC ubicados en zonas montañosas y donde viven los sectores más empobrecidos, con la red de Metro. El sistema, denominado Metrocable, presenta ventajas relativas a la inclusión social de los colectivos desfavorecidos, a su escaso impacto ambiental y a que no provoca congestión.

La moderna red que conforman Metro-Metrobús y Metrocable se combina con la operación en superficie de vehículos "por puesto"; con jeeps o rústicos, vehículos con doce asientos que ofrecen servicios de transporte a los barrios de los cerros; y con

2 El nombre "por puesto" se remonta a los años 60, cuando los automóviles de pasajeros prestaban el servicio libre (taxi) y el "carro por puesto", donde se compartían cinco puestos en el automóvil. El tamaño de los vehículos con los que se ofrecía este servicio fue creciendo hasta las 18 a 32 plazas actuales. 
autobuses de operadores privados y moto-taxis (cuya cantidad se desconoce). En la Venezuela de los años 70, la política "cada conductor un empresario" estimuló el uso del "por puesto"; de ahí que proliferaran los vehículos de baja capacidad y se atomizara el servicio. El transporte se convirtió en una salida fácil para algunos desempleados, que compraron vehículos con sus prestaciones laborales y se convirtieron en transportistas profesionales. Como consecuencia, el autobús prácticamente desapareció, aumentó la congestión de tránsito, empeoraron las condiciones ambientales del área y se redujo el control por parte de las autoridades. La red de transporte colectivo superficial se extendió sin planificación, según el desordenado crecimiento de la ciudad y la lógica del sector privado que operaba en las rutas de mayor demanda.

Aunque formalmente existen organismos del Estado responsables de la prestación del servicio de transporte público urbano, el sector privado lo presta mayoritariamente mediante unas doscientas operadoras de pequeño tamaño, con vehículos habitualmente en pésimas condiciones y un servicio sin control ni regulación, con grave perjuicio para el chofer, que no posee salario fijo, beneficios ni seguro social. ${ }^{3}$ Las redes de autobuses y de "por puesto" han acabado compitiendo en los ejes de operación del Metro, ofreciendo tarifas más bajas a la población de menor renta y enlaces en las estaciones (Mundó Tejada, 2002). La Ley de Tránsito y Transporte Terrestre (2008) asignó la política de transporte al Gobierno Nacional, pero transfirió las competencias de autorizar, regular, supervisar y controlar todo el servicio de transporte público urbano a cada Municipio (Asamblea Nacional, 2008). Teóricamente, el Municipio otorga el derecho de explotación de una determinada ruta a los choferes o dueños de las unidades. En la práctica, la regulación es escasa y se terminan incumpliendo rutas, paradas y frecuencias. Los vehículos "por puesto" funcionan sin horarios y concentran su actividad en las horas punta, cuando existe más demanda (Urdaneta, 2008). Esto dificulta enormemente la coordinación del transporte metropolitano o el suministro de información de rutas y horarios. Además, incrementa la inseguridad, puesto que el sector está desorganizado y desarticulado. Como consecuencia, los costos y tarifas de los servicios de transporte colectivo formal y legalmente establecidos han aumentado y su rendimiento se ha reducido, están perdiendo clientes y trabajan en duras condiciones de congestión vial (CAF, 2005).

De forma particular, se observan diferencias en la ordenación y operación del transporte colectivo entre los distintos municipios del AMC. La Dirección de Transporte y Vialidad de la Alcaldía de Baruta autoriza la puesta en marcha de rutas municipales e intermunicipales, controla la situación de terminales y paradas, fiscaliza las empresas de taxis y desarrolla planes de formación de conducción para operadores de transporte colectivo del municipio (http://www.alcaldiadebaruta.gob.ve). La Alcaldía del Municipio Chacao prioriza la vialidad y ha dotado a su territorio de un sistema de transporte colectivo público (TransChacao) desde 2008, equipado con modernos vehículos y que atiende a unos 35.000 usuarios en día medio labora-

$3 \overline{\text { Los ingresos del chofer provienen del cobro de la tarifa, regulada para facilitar el acceso a la población }}$ de bajas rentas. Los choferes y dueños de las unidades se organizan en cooperativas, asociaciones civiles o sindicatos de transportistas. 
ble. Ha diseñado la ciclovía para promover la bicicleta como alternativa al vehículo motorizado privado y en su página web ofrece datos de velocidad para las principales arterias viales del municipio. El Instituto Autónomo de Tránsito, Transporte y Circulación de Chacao se encarga de la coordinación del transporte, semáforos, señalización y demarcación y ofrece cifras de accidentalidad (http://www.chacao.gob.ve).

\section{Movilidad y consumo de recursos}

El incremento sostenido del parque vehicular privado en América Latina, de 0,08 a 0,17 vehículos por persona en el período 1990-2007, puede explicarse por el aumento de los ingresos, el mayor acceso al crédito y como respuesta a las carencias en el sistema de transporte colectivo (Naciones Unidas \& CEPAL, 2010). En 1982, Caracas ya contaba con una de las mayores tasas de motorización de América Latina (167 vehículos/1.000 habitantes). Actualmente se mantiene entre las ciudades con mayores tasas de motorización de la región (261 vehículos/1.000 habitantes) y con un índice mucho mayor que la media del país (146 vehículos/1.000 habitantes) (CEPAL, 2009). Según la Sociedad Venezolana de Ingeniería Civil, el 60\% de los vehículos vendidos en el país se utiliza en el AMC, donde circulan, cada día, un millón de vehículos residentes, más otro millón procedentes de las subregiones periféricas. Además, mensualmente se incorporan al parque vehicular unas cinco mil motos. La creciente tasa de motorización en la región está provocando mayor consumo de recursos por parte de los vehículos privados (tiempo, espacio, dinero y energía) y fuertes impactos negativos, que incluyen accidentes viales, congestión vehicular, contaminación ambiental y exclusión social.

En el AMC se producen unos cinco millones de desplazamientos diarios, sin considerar los efectuados por los residentes de las conurbaciones. Aunque Caracas posee el salario mínimo más alto del espacio analizado y el precio de la gasolina más bajo, su índice de movilidad (1,6 viajes/hab./día) es inferior a la media de las metrópolis analizadas por el OMU (2 viajes/hab./día) y a la de las ciudades de países desarrollados (3,6 viajes/hab./día), cuyos mayores niveles de movilidad se pueden explicar, principalmente, por los más altos niveles de ingreso y de participación en el mercado laboral formal. El menor índice de movilidad del AMC puede encontrar su explicación en diferencias en el mercado de trabajo, mayor uso de centros comerciales, sustitución de la compra diaria por servicios de chicos-moto o altos índices de inseguridad en las calles (Vasconcellos, 2005). El índice de movilidad varía por municipios, y destaca Chacao con 4,4 viajes/hab./día (Cuadro 3). El Hatillo, en el sureste de Caracas, es un municipio privilegiado con urbanizaciones, comercios exclusivos y zonas recreacionales con el índice de movilidad más bajo (1,1 viajes/hab./día) (http://www.alcaldiaelhatillo.gob.ve).

Respecto de los modos empleados en el área de estudio del OMU, la mayor parte de los viajes se realiza en transporte colectivo (43\%), mientras que los viajes en vehículo privado motorizado y modos no motorizados tienen una importancia 
similar (28\%). En Caracas destaca la baja importancia del modo peatonal y ciclista, 10 puntos por debajo de la media del país (18\%), algo que se puede entender si tomamos en cuenta la alta inseguridad en las calles y la baja preferencia vial para estos modos. Esta carencia da como resultado que los viajes en transporte colectivo tengan una importancia 10 puntos superior a la media del área (Cuadro 3). Discriminando por municipios, en El Hatillo y Baruta los viajes en modos privados motorizados son más de la mitad, mientras que en Libertador y Sucre la proporción de viajes realizados en medios colectivos y no motorizados supera la media del AMC, situándose en un $80 \%$. Estas disparidades en el modelo de movilidad son indicativas de desigualdades socioeconómicas y ponen de manifiesto que las políticas orientadas al mayor uso del vehículo privado no favorecerán de forma equitativa a los caraqueños (Flórez, 2008; Vasconcellos, 2002; 2010a).

En el área de estudio del OMU, el 85\% de los viajes en transporte colectivo se realiza en superficie y sobre ruedas. En el AMC destaca la gran importancia de los desplazamientos (47,86\%) en unidades "por puesto", con más de 18.000 microbuses y combis que circulan por medio millar de rutas terrestres, agravando la congestión de tráfico y reduciendo la velocidad de circulación. Al transporte sobre rieles corresponden catorce millones de viajes al día, lo que representa un 15\% del total de viajes diarios (Gráfico 1) (Mundó Tejada, 2008; CAF, 2010). Esta situación revela la escasez de una red de autobuses de mayor calidad.

Cuadro 3 | Índices de movilidad en el AMC, 2005 y 2007. Reparto modal y comparación con zona OMU (número viajes/día y número viajes/hab./día)

\begin{tabular}{|c|c|c|c|c|c|c|}
\hline AÑo & MUNICIPIO & $\mathrm{N}^{\circ}$ DE VIAJES/DÍA & $\begin{array}{c}\text { T. PRIVADO } \\
\text { MOTORIZADO } \\
(\%)\end{array}$ & $\begin{array}{l}\text { T. COLECTIVo } \\
(\%)\end{array}$ & $\begin{array}{c}\text { A PIE/ } \\
\text { BICICLETA (\%) }\end{array}$ & $\begin{array}{c}\mathrm{N}^{o} \text { VIAJES/ } \\
\text { HAB./DÍA }\end{array}$ \\
\hline \multirow[t]{6}{*}{2005} & Libertador & 3.204 .746 & 18,3 & 62,7 & 19,1 & 1,5 \\
\hline & Sucre & 918.793 & 22,2 & 55,3 & 22,5 & 1,5 \\
\hline & Chacao & 314.945 & 35,8 & 53,6 & 10,7 & 4,4 \\
\hline & El Hatillo & 68.649 & 54,2 & 26,0 & 19,8 & 1,1 \\
\hline & Baruta & 417.528 & 57,0 & 31,1 & 11,9 & 1,4 \\
\hline & $A M C$ & 4.924.661 & 23,9 & 57,5 & 18,6 & 1,6 \\
\hline \multirow[t]{2}{*}{2007} & $A M C$ & 4.966 .136 & 27,2 & 54,4 & 18,4 & 1,6 \\
\hline & Zona $O M U$ & 214.130 .584 & 28,6 & 43,1 & 28,3 & 2,0 \\
\hline
\end{tabular}

FUente Datos de 2005: Elaboración Propia a partir de INE y AlCaldía Metropolitana de Caracas/Instituto Metropolitano de Transporte (INMETRA), 2005; DATOS DE 2007: CAF, 2010. 
GRÁFICO 1 | Distribución de los viajes transporte colectivo en AMC y Zona OMU, 2007 (porcentajes)

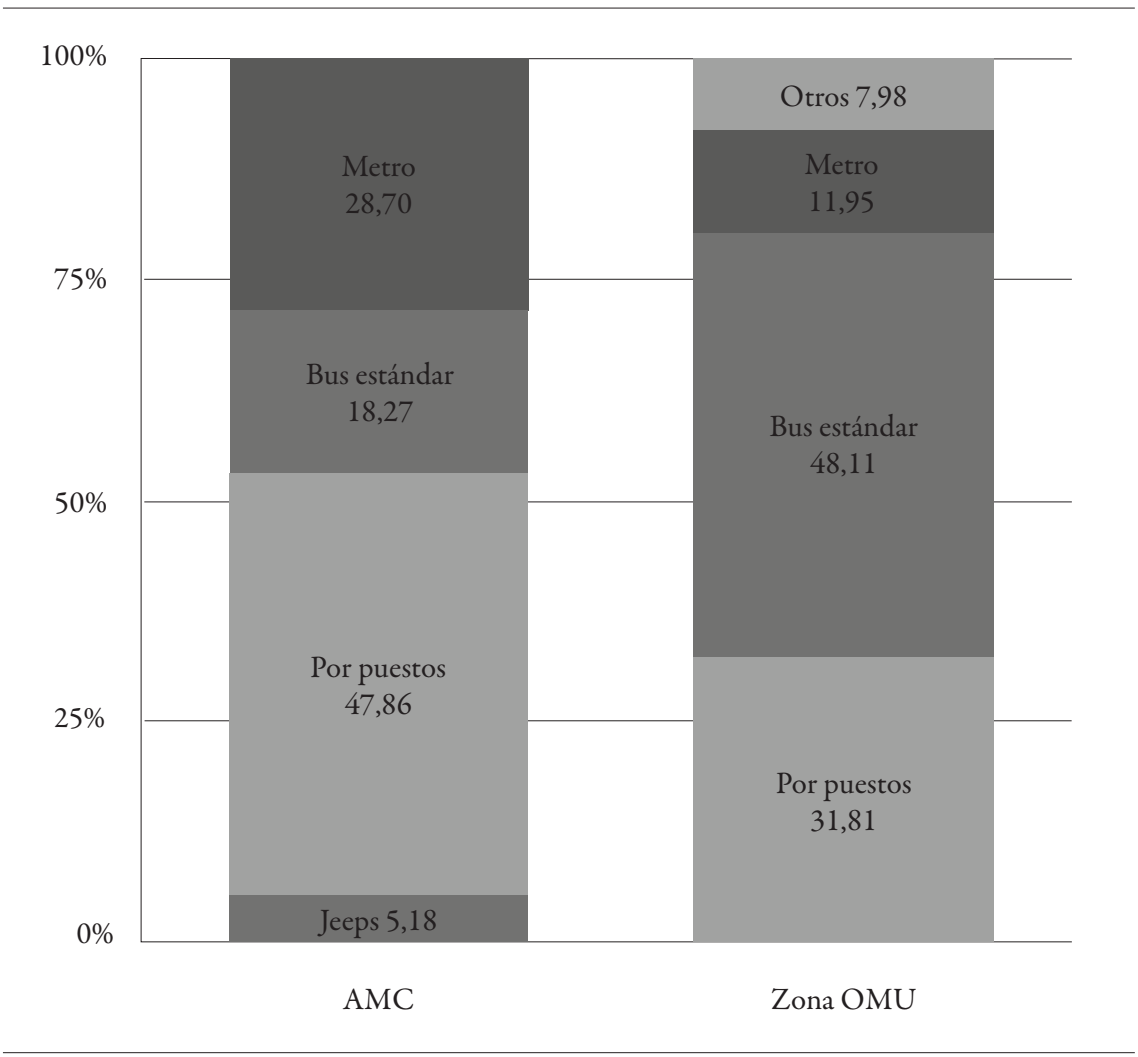

FUente Elaboración Propia a PARTir de CAF, 2010.

Los recursos aplicados en la movilidad se pueden analizar para cuatro aspectos: consumo de espacio, costos de operación de vehículos, tiempo de recorrido y energía utilizada.

Para conocer las disparidades en cuanto a ocupación del sistema vial por los distintos vehículos, se puede analizar la distancia media recorrida por transporte individual y colectivo. El binomio mejoras tecnológicas de los vehículos/descentralización urbana aumenta la longitud de los viajes sin modificar las motivaciones. Se logra más movilidad, pero no mayor accesibilidad (Vasconcellos, 2010a). En la zona de estudio del OMU, el 89\% de la distancia recorrida diariamente (542 millones de kilómetros) corresponde a automóviles y taxis, aunque solo realizan el 28\% de los viajes. En el AMC, el 79\% de los recorridos es realizado por automóviles y taxis, lo que da idea de la invasión del espacio público por lo individual (Gráfico 2) (Ocaña, 2008). Los recorridos a pie (1,2 km/hab./día) están por debajo de la media $(1,4 \mathrm{~km} / \mathrm{hab} . / \mathrm{dí})$ y las distancias mayores se recorren para llegar a los vehículos y caminar desde estos hasta los destinos finales. 
GRÁFICO 2 | Recorridos diarios de los vehículos motorizados en AMC y zona OMU (porcentajes), 2007

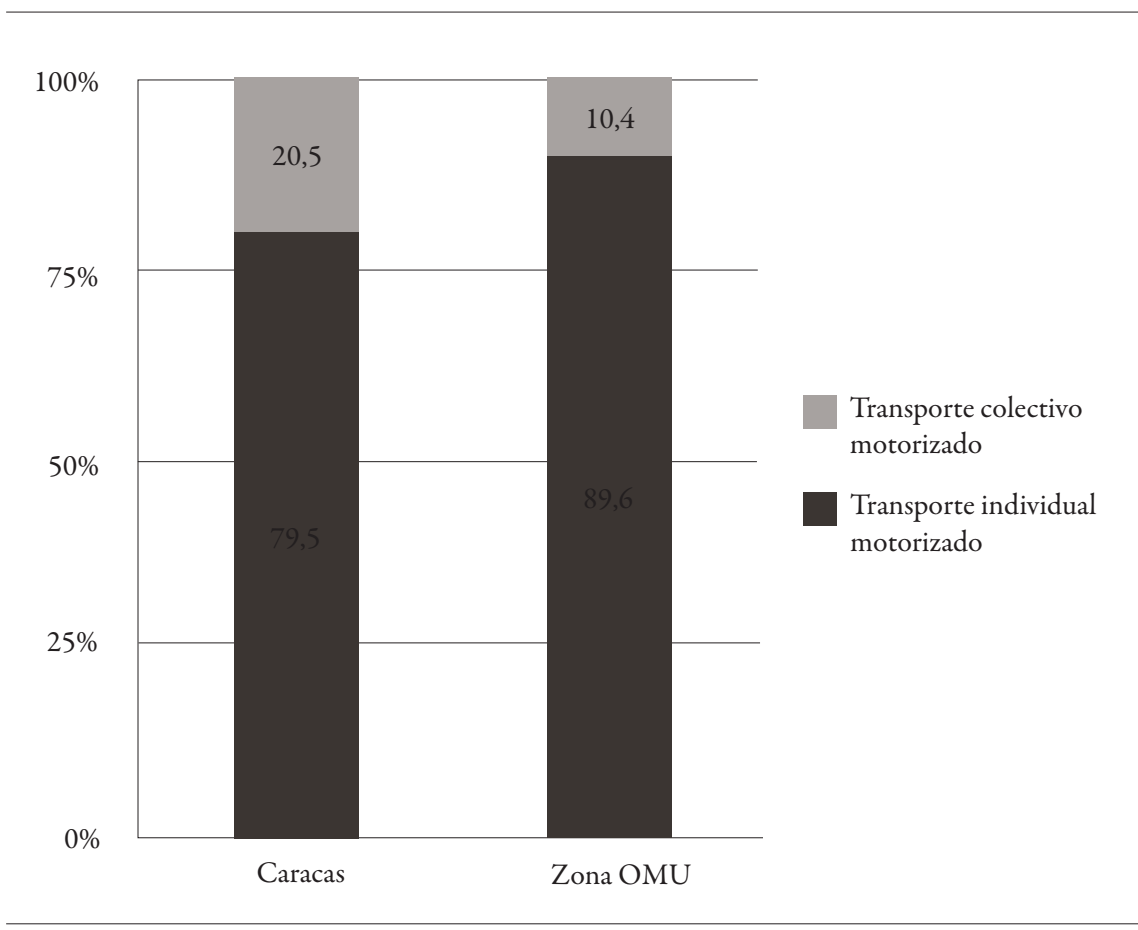

FUENTE Elaboración PROPIA A PARTIR DE CAF, 2010.

Otro factor que influye en los usos del transporte es su costo. Esto es particularmente válido para las familias de recursos escasos, que optan por la caminata en el total del trayecto o en una parte de él para reducir el gasto en este ítem. Considerando esta realidad, se tiene que las tarifas bajas son un elemento de integración (Avellaneda, 2008; Cebollada \& Avellaneda, 2008). En el AMC es especialmente importante esta estrategia, puesto que la proporción de gastos asociados a la movilidad en transporte colectivo supone un $43 \%$, muy por encima de la media de la zona OMU (22\%) (CAF, 2010).

Los habitantes de las áreas metropolitanas latinoamericanas dedican 118 millones de horas a desplazamientos, lo que corresponde a 1,1 horas/día. La mayor parte del tiempo (62\% del total) se consume en el uso del transporte colectivo, pese a que tan solo el 10\% de los recorridos se realiza en él. En Caracas, el 64\% del tiempo de recorrido se utiliza en los modos colectivos (Gráfico 3). El recorrido medio dura 1,04 horas y oscila entre los 10 minutos y las 3 horas. Además, el tiempo de viaje medio en autobús es el segundo más alto en este medio ( 67 minutos) después de Bogotá (73 minutos), mientras que la media de tiempo de viaje en automóvil en la zona de estudio es de 30 minutos. 
GRÁfICO 3 | Consumo de tiempo de recorrido por modo en AMC y zona OMU (porcentajes), 2007

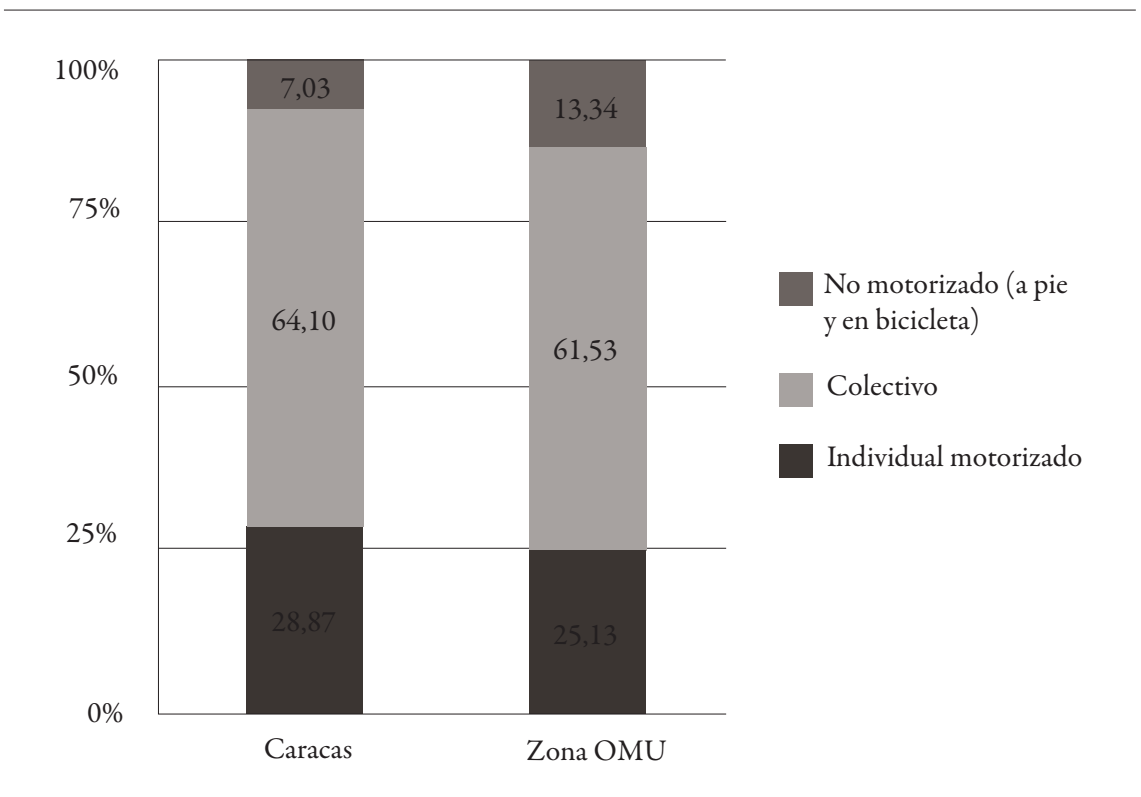

FUENTE ELABoración PROPIA A PARTIR DE CAF, 2010.

Respecto del consumo de energía, Caracas es la metrópoli latinoamericana con el menor precio de la gasolina y el mayor consumo (670 GEP [Gramos Equivalentes de Petróleo]/hab./día). En promedio, en las quince áreas OMU, el 75\% del combustible es consumido por el transporte individual y en el AMC esa proporción asciende al 68\%. La diferencia se puede deber al gran número de vehículos "por puesto" que circulan y a la influencia de la antigüedad de la flota en el consumo de combustible. Estas cifras no deben dar lugar a engaño, ya que el consumo de energía por viaje en transporte individual es de 606 GEP, mientras que en transporte colectivo es igual a 164 GEP.

A modo de resumen, como se comentó en la metodología, el cálculo del índice de importancia porcentual del uso de cada recurso j sobre el peso de los desplazamientos por modo $\left(\mathrm{I}_{\mathrm{r} / \mathrm{d}}^{\mathrm{j}}\right)$, indica si el modo i está efectuando una sobreutilización del recurso cuando es superior a 100. Los resultados demuestran que los usuarios de transporte individual motorizado sobreutilizan el sistema vial y los recursos energéticos. En cambio, el índice de tiempo pone de manifiesto que el empleado en transporte colectivo es alto en relación con su importancia (Cuadro 5). En definitiva, recorridos más largos en automóvil con empleo de menor cantidad de tiempo, combustible barato, mayor comodidad y más seguridad, es igual a congestión vial para transporte privado y colectivo, lo que permite concluir que quien pueda elegir no utilizará el transporte colectivo. Se produce, en consecuencia, una brecha de 
movilidad traducida en una gran diferencia entre la tasa de movilidad por clases sociales y grupos: la población de mayores ingresos viaja en vehículo privado, mientras que el resto se traslada en los medios más inseguros e incómodos.

\section{CUADRO 4 | Índice de consumo comparado de recursos del transporte motorizado} en AMC y zona OMU $\left(\mathbf{I}_{\text {rd }}^{i}\right)$

\begin{tabular}{l|cc|cc}
\hline & $\begin{array}{c}\text { T. PRIVADO } \\
\text { MOTORIZADO }\end{array}$ & T. COLECTIV & \\
\hline & AMC & OMU & AMC & OMU \\
\hline Espacio & 296 & 321 & 37 & 23 \\
Tiempo & 107 & 89 & 119 & 142 \\
Costo & 211 & 279 & 80 & 51 \\
Energía & 252 & 268 & 59 & 58 \\
\hline
\end{tabular}

FUeNTE Elaboración PRopia A PARTiR de CAF, 2010.

\section{Impactos negativos del modelo de movilidad}

Como se ha anticipado a lo largo del trabajo, la configuración actual del modelo de movilidad urbana en el AMC está provocando fuertes impactos negativos. A continuación se analizarán los accidentes de tránsito, la congestión vial y la contaminación atmosférica, dada la falta de datos sobre contaminación acústica; y se expondrá la relación entre movilidad, pobreza y exclusión social.

Según la Organización Mundial de la Salud, América Latina tiene las mayores cifras de víctimas mortales en accidentes de tráfico (26,1 muertes/100.000 hab.), y los datos sobre la distribución de las muertes muestran la vulnerabilidad de los peatones. En la región, los peatones suponen más de la mitad de las víctimas mortales, mientras que el problema en Canadá y Estados Unidos se centra en los ocupantes de los vehículos. Estas cifras son sumamente elevadas si se las comparan con las de ciudades europeas (World Health Organization [WHO], 2010). Según el OMU, el número de muertes producidas por accidentes viales en las metrópolis consideradas asciende, anualmente, por término medio, a 9,6 fallecidos/100.000 hab.

Según datos del Ministerio de Salud venezolano, los accidentes de tránsito son la quinta causa de muerte en el país, siendo el transporte colectivo el que arroja peores cifras. Según el Ministerio del Poder Popular para la Infraestructura (MINFRA), en 2006 se produjeron más de 6.000 muertes y 41.000 lesiones no fatales, lo que sitúa a Venezuela como el país en el número catorce de mortalidad viaria por millón de habitantes en el mundo (Ojeda, 2008) y a Caracas como la undécima urbe en mortalidad viaria en el mundo (UITP, 2003a). Según datos del OMU, 
en Caracas se alcanza a 5,96 defunciones/100.000 hab., aunque la propia fuente destaca que esta cifra podría estar subestimada. En el primer cuatrimestre de 2007, el Cuerpo de Bomberos Metropolitanos registró un aumento de la accidentalidad de $40 \%$ respecto del año anterior. Además, se produjeron más de dos centenas de accidentes con motos. Las lesiones causadas por el tránsito provocan daños psicológicos a los familiares e, incluso, el empobrecimiento de los hogares donde se pierde a la persona que aportaba los ingresos (WHO, 2010). La Agencia Bolivariana de Noticias (http://www.abn.info.ve) advierte que son la principal causa de defunción de la población joven, debido al mal estado de calles y carreteras y al incumplimiento de las normas de seguridad vial. Por supuesto, la normatividad incide en la accidentalidad viaria. En Uruguay y Venezuela no se obliga a los fabricantes de vehículos a la instalación de cinturones de seguridad en todos los asientos y la tasa de utilización del casco en la motocicleta es del 55\%.

La congestión vial es un problema local que aparece cuando la incorporación de un vehículo adicional reduce la velocidad de circulación de los demás y redunda en un aumento de los costos de movilidad, de los tiempos de viaje y de la incertidumbre (Kenneth, 1997; Lizarraga 2006b). La congestión vial en el AMC es muy alta debido a la escasa regulación, a la inexistencia de soluciones alternativas al vehículo privado que permitan desplazarse con seguridad, a la mala señalización y a vías que no están diseñadas para la gran cantidad de vehículos motorizados que circulan por ellas. Su sistema de transportes por carretera se desarrolló rápidamente en las décadas de los 50 y 70, pero desde la construcción de la Cota Mil no se ha invertido en grandes infraestructuras, ni se ha avanzado firmemente en una dirección alternativa al uso intensivo del vehículo privado. Las principales autopistas y avenidas están dispuestas en dirección este-oeste, frente a la escasez y deficiencia de las vías nortesur (Alcaldía Metropolitana de Caracas/INMETRA, 2006). A esto hay que añadir, según las proyecciones del Instituto Nacional de Transporte Terrestre (INTT), que la tasa de subregistros es del $50 \%$ de los vehículos, lo que desvirtúa cualquier política de reducción de la congestión de tránsito. Según la Sociedad Venezolana de Ingeniería Civil, la estructura vial del AMC solo está preparada para atender el $30 \%$ del parque automotor total, lo que provoca una reducción de la velocidad promedio $(11-15 \mathrm{~km} / \mathrm{h}$ ) y un aumento del costo, energía y tiempo. El bajo precio del combustible, el fuerte crecimiento del parque automotor, ${ }^{4}$ la infraocupación de los vehículos privados (1,2 personas/vehículo) y las pésimas condiciones de vialidad extendidas a todos los modos, indican la gravedad del problema y la necesidad de adoptar medidas urgentes (Nagel, 2007).

En los años 80, en Caracas se implantó el "día de parada" para reducir la congestión, restringiendo la circulación de los automóviles por número de matrícula. En 2007, las alcaldías de Chacao y Baruta pusieron en marcha el plan Pico y Placa;

4 Según la Asociación de Logística de Venezuela (ALV), en el período 2005-2007 se vendió más de un millón de vehículos. No obstante, el promedio mensual de ventas comenzó a descender a partir de 2008 y el descenso continuó en 2009 (ALV, 2009). 
y la Alcaldía Metropolitana, el programa Vía Libre, suspendido por el Tribunal Supremo de Justicia por considerarlo una violación del derecho al libre tránsito por el territorio nacional (Alcaldía Metropolitana de Caracas/INMETRA, 2009).

Los altos niveles de densidad poblacional, la congestión de tránsito y la actividad industrial que caracterizan Caracas, provocan altos niveles de contaminación medioambiental (Sucre, 1997). En el AMC el transporte colectivo es responsable de la emisión del 35\% de los contaminantes locales, cifra superior a la media de la zona OMU (15,6\%), lo que refleja las precarias condiciones de la flota y la menor importancia relativa de los viajes a pie y en bicicleta (Gráfico 4).

Gráfico 4 | Emisión de contaminantes locales por modos de transporte en Caracas y total zona OMU (porcentajes), 2007

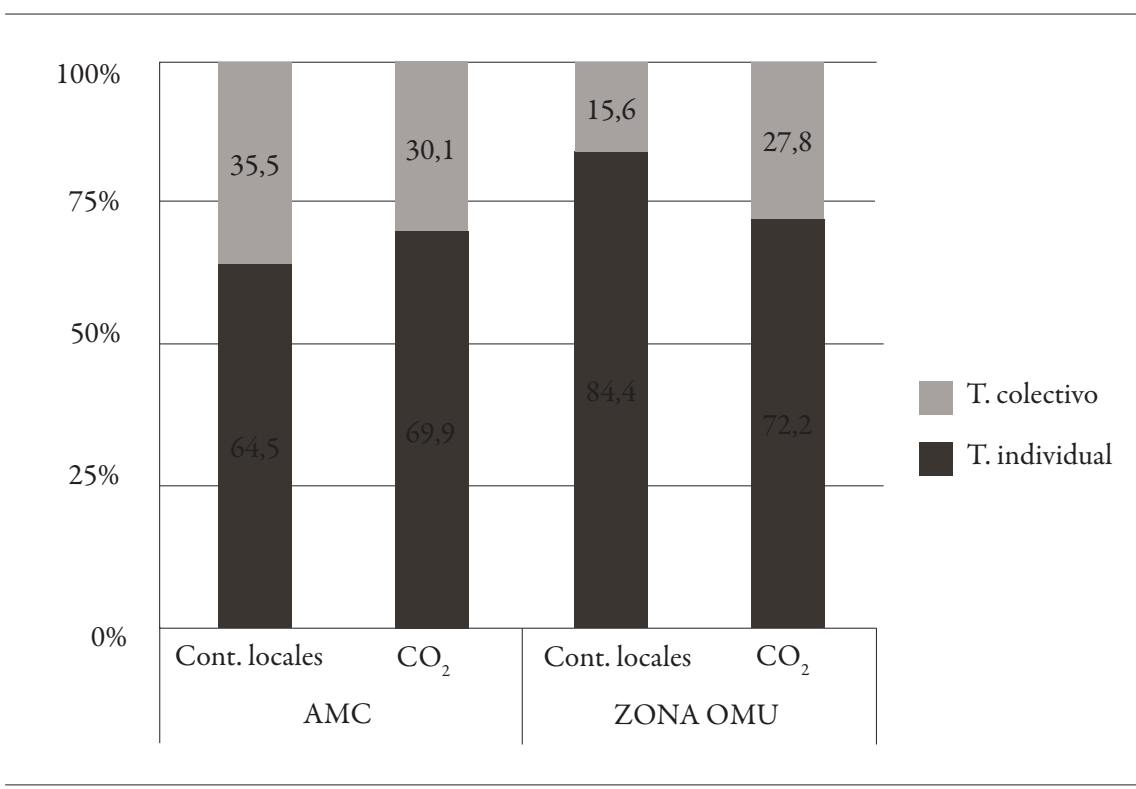

FUENTE ELABoración PRopia A PARTIR DE CAF, 2010.

Además de los costos externos del transporte considerados tradicionalmente por la literatura, otro impacto negativo del modelo de movilidad actual, de especial relevancia en la región latinoamericana, se refiere a la exclusión social. Según la CEPAL, en 2009 la región enfrentaba los mayores niveles de desigualdad del mundo y la incidencia de la pobreza alcanzó a 33,1\% de la población. En Venezuela (27,6 millones de habitantes), una tercera parte de la población vive en condiciones de pobreza, pero los índices de desigualdad están entre los menores de América Latina. El AMC cuenta con el mayor ingreso promedio por persona del país $(163,05$ sobre una media igual a 100 según datos de 2005), pero con los mayores índices de desigualdad por ingresos del país (Fernández, Torres, Urdaneta \& Vargas, 2008). 
Esta polarización en el nivel de renta provoca conflictos de intereses que derivan en un círculo vicioso de la degradación del transporte urbano (Figura 2). Las clases medias y altas, propietarias de vehículos privados, principales causantes de la congestión vial, presionan a favor de la inversión en autopistas urbanas. Los estratos de rentas bajas se dividen entre los que pueden acceder al sistema de transporte colectivo, que soporta idénticos niveles de congestión que el transporte privado; y los que se ven obligados a optar por la caminata, la bicicleta o modos de transporte informales, degradados e inseguros (Figueroa, 2005; Lazo, 2008). Ambos sufren la inseguridad de una urbe donde se contabiliza más de la mitad de los crímenes violentos de Venezuela (United Nations-Habitat, 2007). Estos hechos han llevado a la alcaldía del municipio de Sucre a establecer medidas como un muro perimetral, barreras electrónicas o cámaras de vigilancia (http://www.alcaldiamunicipiosucre.gov.ve). El municipio Libertador, donde se concentra más de la mitad de la población del área, creó, en 2002, el Instituto Autónomo de Seguridad Ciudadana y Transporte (INSETRA) con el fin de mejorar la seguridad, preservar las infraestructuras municipales y defender a la población ante situaciones de accidentes, emergencias y desastres naturales (http://www.caracas.gov.ve). A ello debe agregarse que los obstáculos o problemas relativos a la movilidad no están asociados únicamente a la pertenencia a los colectivos más desfavorecidos, ya que las características asociadas al género y edad son un determinante que restringe o amplía las posibilidades de acceso a las oportunidades que brinda la ciudad. Por otra parte, al no existir infraestructuras adecuadas para el desplazamiento de peatones ni de bicicletas, aumenta la accidentalidad urbana y empeoran las condiciones de calidad del aire.

Las políticas de transporte desarrolladas durante las últimas décadas se han centrado en el fomento de la movilidad privada motorizada y la liberalización del transporte público colectivo. Estas estrategias han ido en detrimento de los colectivos cautivos de este modo de transporte, por la eliminación de los subsidios y el aumento de las tarifas. Además, la formalización del sistema de transporte colectivo no garantiza avanzar hacia la cohesión social, especialmente cuando se aplican criterios economicistas en su planificación, ya que se dejan áreas del territorio y franjas horarias sin cubrir (Cebollada \& Avellaneda, 2008; Avellaneda, 2007, 2008, 2011). En algunas metrópolis latinoamericanas se está persiguiendo un objetivo de movilidad que encierra una contradicción, fruto de los conflictos físicos y políticos de circulación: por una parte, más transporte colectivo con inversión en sistemas integrados de transporte masivos (SITM) (Caracas tiene prevista la creación del SITM BusCaracas); y por otra, más transporte individual con inversión en autopistas urbanas (Plan Vial Caracas 2025). Aunque esta última medida puede solucionar a corto plazo el problema de congestión vehicular, también aporta más incentivos para utilizar el automóvil y no cambia el problema estructural de movilidad, puesto que a mediano plazo nuevamente se genera congestión (Lupano \& Sánchez, 2008). 


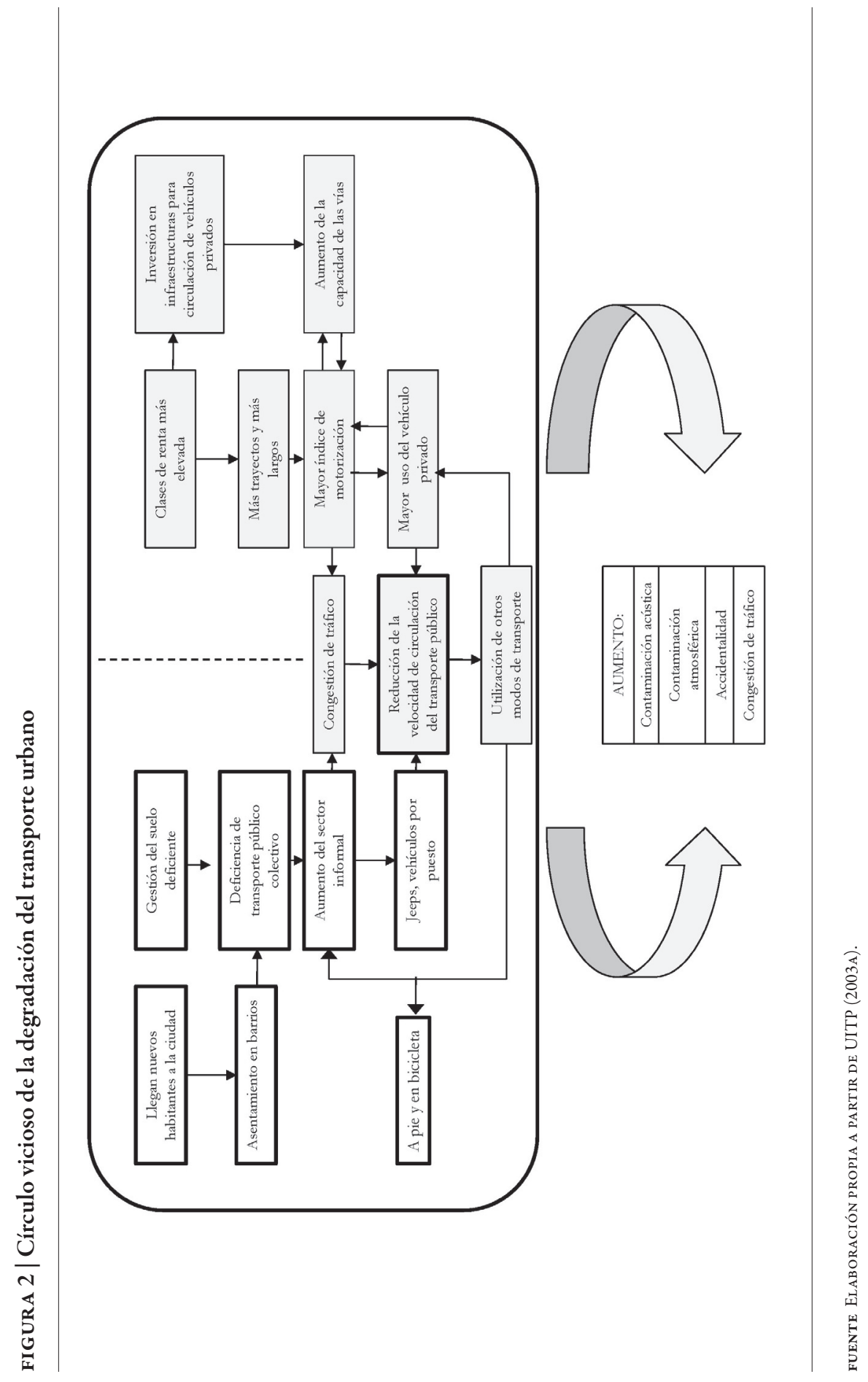




\section{Conclusiones}

El propósito de este trabajo ha sido exponer las características del modelo de movilidad urbana en el AMC, ligado a la expansión territorial, y sus efectos negativos, a partir de los datos estadísticos existentes y de las aportaciones teóricas recientes.

El modelo de movilidad configurado en América Latina presenta severos problemas de accidentalidad, congestión y baja calidad del aire, que se unen a la inseguridad ciudadana y la exclusión social. Los individuos de ingresos medios y altos habitan en zonas residenciales y usan intensivamente el vehículo privado. Los grupos de rentas bajas viven en zonas periurbanas donde predominan asentamientos informales; carecen de servicios educativos y sanitarios y de oportunidades laborales; y utilizan, predominantemente, el transporte colectivo o recurren a la caminata insegura o a estrategias informales de desplazamiento. El modelo de movilidad del AMC, según los indicadores analizados, es similar al que presentan, por término medio, las metrópolis estudiadas por el OMU, con una fuerte brecha de movilidad según características socioeconómicas y personales, aunque destaca el mayor peso en el conjunto de los desplazamientos de las unidades "por puesto". La escasa preferencia vial e inseguridad que sufren peatones y ciclistas explica la baja participación de los modos no motorizados. El uso del automóvil presenta mayores ventajas relativas, porque permite recorrer más espacio en menos tiempo, la gasolina es muy barata, no soporta peores condiciones de congestión que el transporte colectivo, es más cómodo y más seguro.

En Caracas coexisten una moderna red de transporte público colectivo compuesta por el sistema Metro-Metrobús-Metrocable, y una desordenada red de unidades "por puesto" con intercambiadores y vehículos en condiciones precarias. Hay áreas del territorio y franjas horarias sin cubrir, lo que convierte a los colectivos sin coche en los más desfavorecidos. Las inversiones en transporte público se deben complementar con el control de las obligaciones tributarias de los propietarios de los vehículos privados y el fortalecimiento del transporte colectivo.

Algunas medidas para avanzar hacia una movilidad urbana sostenible incluyen la ampliación y mejora de infraestructuras seguras para peatones y ciclistas, de manera de aumentar su grado de accesibilidad; la reducción del uso del vehículo privado y la reorganización del transporte colectivo. En Europa están funcionando los consorcios de transportes metropolitanos y se podría pensar en su implantación en el AMC, con la inclusión de alcaldías y operadores, para incrementar la coordinación de los distintos agentes y el control de las rutas y frecuencias y perseguir la integración tarifaria que reduciría la presión para el usuario y permitiría el trasbordo entre modos metropolitanos y urbanos.

La reducción del uso del vehículo privado en el AMC podría lograrse con un impuesto a la gasolina que se trasladara a un fondo por la movilidad urbana sostenible. Igualmente, el reordenamiento del caos circulatorio pasa por el cumplimiento de la fiscalidad y el control del subregistro de vehículos. El racionamiento al uso del vehículo privado no es una alternativa factible en el largo plazo para solucionar los problemas de congestión vial. 
En definitiva, la movilidad urbana sostenible pasa por "repensar las ciudades", coordinando las políticas de uso del suelo con la organización y operación del transporte colectivo para disminuir las distancias recorridas, dar prioridad al transporte colectivo, construir infraestructuras seguras para peatones y ciclistas, hacer cumplir las normas de tránsito e implementar programas de educación y sensibilización. IEURE

\section{Referencias bibliográficas}

Alcaldía Metropolitana de Caracas \& Instituto Metropolitano de Transporte (INMETRA). (2005). Encuesta de movilidad. Caracas: Alcaldía Metropolitana de Caracas.

Alcaldía Metropolitana de Caracas \& Instituto Metropolitano de Transporte (INMETRA). (2006). El sistema de transporte en el distrito metropolitano de Caracas. Caracas: Alcaldía Metropolitana de Caracas.

Alcaldía Metropolitana de Caracas \& Instituto Metropolitano de Transporte (INMETRA). (2009). Programa Vía Libre. Caracas: Alcaldía Metropolitana de Caracas.

Asamblea Nacional Constituyente. (2000). Ley especial sobre el régimen del distrito metropolitano de Caracas. Gaceta oficial de la República Bolivariana de Venezuela, 36.906 (8 de marzo). Caracas.

Asamblea Nacional. (2008). Ley de Tránsito y Transporte Terrestre. Gaceta Oficial 363(052). Venezuela.

Asociación de Logística de Venezuela (ALV). (2009). Estadísticas de interés (revisión marzo). Caracas. Disponible en http://www.alv-logistica.org/docs/Estad\%C3\%ADsticas2008RevMar2009. pdf

Avellaneda, P. (2007). Movilidad, pobreza y exclusión social. Un estudio de caso en la ciudad de Lima. Tesis doctoral. Departament de Geografia, Universitat Autònoma de Barcelona.

Avellaneda, P. (2008). Movilidad, pobreza y exclusión social en la ciudad de Lima. Anales de Geografía de la Universidad Complutense, 28(2), 9-35.

Avellaneda, P. (2011). Movilidad y pobreza en la ciudad latinoamericana. En II Encuentro Iberoamericano de Movilidad Urbana Sostenible. Un diálogo Europa-América Latina. Bogotá: Asociación Iberoamericana de Movilidad Urbana para la Sostenibilidad (ASIMUS).

Banco Mundial. (2002). Ciudades en movimiento. Revisión de la estrategia de transporte urbano del Banco Mundial. Washington, DC: Banco Internacional para la Reconstrucción y el Desarrollo/Banco Mundial.

Barrios, S. (2001). Áreas metropolitanas ¿Qué ha cambiado? La experiencia de la Caracas Metropolitana. EURE, 27(80), 59-86. doi: 10.4067/S0250-71612001008000004

Cariola C. \& Lacabana, M. (2003). Globalización y desigualdades socioterritoriales. La expansión de la periferia metropolitana de Caracas. EURE, 29(87), 5-21. doi: 10.4067/S0250-71612003008700001

Cass, N., Shove, E., \& Urry, J. (2005). Social exclusion, mobility and access. The Sociological Review, 53(3), 539-555. doi: 10.1111/j.1467-954X.2005.00565.x

Cebollada, Á. \& Avellaneda, P. (2008). Equidad social en movilidad: Reflexiones en torno a los casos de Barcelona y Lima [Coloquio Internacional de Geocrítica $\left(10^{\circ}, 2008\right.$. Barcelo- 
na)]. Scripta Nova, Revista Electrónica de Geografia y Ciencias Sociales, 12(270). Disponible en http://www.ub.edu/geocrit/sn/sn-270/sn-270-47.htm

Clichevsky, N. (2000). Informalidad y segregación urbana en América Latina. Serie Medio Ambiente y Desarrollo, 28. Santiago: Comisión Económica para América Latina y el Caribe (CEPAL).

Clout, H. D. (1974). The growth of second-home ownership. An example of seasonal suburbanization. En H. J. Johnson (Ed.), Suburban growth. Geographical processes at the edge of the Western city (pp. 101-128). Aberdeen: Wiley and Sons.

Comisión Económica para América Latina y el Caribe (CEPAL). (2009). Anuario Estadístico de América Latina y el Caribe. Santiago: CEPAL/CELADE (División de Población de CEPAL).

Corporación Andina de Fomento (CAF). (2005). El transporte urbano en América Latina y la situación actual en Colombia. Bogotá: Autor.

Corporación Andina de Fomento (CAF). (2010). Informe del Observatorio de Movilidad Urbana de América Latina. Bogotá: Autor.

Da Silva, A. N. R., Da Silva Costa, M., \& Macedo, M. H. (2008). Multiple views of sustainable urban mobility. The case of Brazil. Transport Policy, 15(6), 350-360. doi: 10.1016/j .tranpol.2008.12.003

Daly, H. (1990). Toward some operational principles of sustainable development. Ecological Economics, 2(1), 1-6. doi: 10.1016/0921-8009(90)90010-R

Estevan, A. \& Sanz, A. (1996). Hacia la reconversión ecológica del transporte en España. Madrid: Los Libros de la Catarata.

European Commission. (2001). Integrated policy aspects of sustainable mobility. Thematic synthesis of transport research results. Paper 1. [Publicado por 'The EXTRA project', en el marco del Programa 'European Community's Transport RTD', septiembre 2001]. Disponible en http://www.ocs.polito.it/biblioteca/mobilita/IntegratedAspectsEXTRA.pdf

Fernández, L., Torres, W., Urdaneta, L. \& Vargas, J. (2008). Distribución del ingreso en Venezuela. Colección Economía y Finanzas. Serie Documentos de Trabajo, 99. Caracas: Banco Central de Venezuela.

Figueroa, O. (2005). Transporte urbano y globalización. Políticas y efectos en América Latina. EURE, 31(94), 41-53. doi: 10.4067/S0250-71612005009400003

Figueroa, O. (2007). Políticas públicas de movilidad y transporte en América Latina. Movilidad Amable (Centro de Transporte Sustentable de México), 4, 21-30.

Flórez, J. (1999). Attracting higher income class to public transport in socially clustered cities. The case of Caracas. European Transport Conference, Proceedings of Seminar B: Transport Planning. Policy and Practice. Cambridge: PTRC. También publicado en Revista de Urbanismo [Universidad de Chile, Facultad de Arquitectura y Urbanismo], 2 (2000); disponible en http:// www.cyberhumanitatis.uchile.cl/index.php/RU/article/view/12312

Flórez, J. (2008). Transporte urbano y desarrollo sostenible. Problemática, propuestas y casos exitosos. En Seminario Internacional Ciudades más sostenibles para América Latina. Caracas, 4 y 5 de noviembre de 2008.

Gakenheimer, R. (1999). Urban mobility in the developing world. Transportation Research Part A, vol. 33, 671-689.

Gerencia de Sistema de Información Geográfica Metropolitano. (2009). Caracas en un click. Caracas: Alcaldía Metropolitana. Disponible en http://www.caracasenunclick.com 
Gerencia Ejecutiva de Transporte Metro. (2009). Metro de Caracas en Cifras. Venezuela: Ministerio del Poder Popular para la Infraestructura.

Giraldo, F., García, J., Ferrari, C. \& Bateman, A. (2009). Urbanización para el desarrollo humano. Politicas para un mundo de ciudades. Londres: United Nations-Habitat.

González-Casas, L. (1999). Los corredores de la modernidad: Movilidad y planificación urbana en Caracas. En X Congreso Latinoamericano de Transporte Público (X CLATPU): Los desafíos frente a la congestión y el transporte público. Caracas, diciembre.

Gudmundsson, H., \& Hojer, M. (1996). Sustainable development principles and their implications for transport. Ecological Economics, 19(3), 269-282. doi: 10.1016/S0921-8009(96)00045-6

Hansen, W. G. (1959). How accessibility shapes land use. Journal of the American Institute of Planners, 25(2), 73-76. doi: 10.1080/01944365908978307

Hine, J. \& Mitchell, F. (2001). Better for everyone? Travel experiences and transport exclusion. Urban Studies, 38(2), 319-332.

INFRAS/IWW. (1999). External effects of transport. Zúrich/Karlsruhe: INFRAS.

INFRAS/IWW. (2004). External Costs of Transport. Update Study. Zúrich/Karlsruhe: INFRAS. Instituto Nacional de Estadística (INE), Venezuela. (1991-2001). Censos de población. Caracas: Autor.

Kenneth, G. (1997). The value of time in economic evaluation of transport projects; Lessons from recent research. Washington, DC: World Bank.

Kenyon, S., Lyons, G., \& Rafferty, J. (2002). Transport and social exclusion. Investigating the possibility of promoting inclusion through virtual mobility. Journal of Transport Geography, 10(3), 207-209. doi:10.1016/S0966-6923(02)00012-1

Lazo, A. (2008). Transporte, movilidad y exclusión. El caso de Transantiago en Chile. [Coloquio Internacional de Geocrítica (10², 2008. Barcelona)]. Scripta Nova, Revista Electrónica de Geografia y Ciencias Sociales, 12(270). Disponible en http://www.ub.edu/geocrit/sn/sn-270/ sn-270-45.htm

Litman, T. (2010). Evaluating transportation equity. Canadá: Victoria Transport Policy Institute.

Lizarraga, C. (2006a). Movilidad urbana sostenible. Un reto para las ciudades del siglo XXI. Economia, Sociedad y Territorio, 6(22). Zinacantepec, México.

Lizarraga, C. (2006b). Propuestas teóricas y prácticas sobre la congestión de tráfico urbano y su tarificación. Ekonomiaz, 61. San Sebastián, España.

Lupano, J. \& Sánchez, R. (2009). Políticas de movilidad urbana e infraestructura urbana de transporte. Serie Documentos de Proyectos, 230. Santiago: Comisión Económica para América Latina y el Caribe (CEPAL).

Maddison, D., Pearce, D., Johansson, O., Calthrop, E., Litman, T., \& Verhoef, E. (1996). The true costs of road transport. Londres: The Centre for Social and Economic Research on the Global Environment (CSERGE).

Metzner, S. \& Verma, A. (2008). Developing urban transport strategies. A case study of Caracas, Venezuela. Indian Journal of Transport Management, 32(1), 42-56.

Miralles, C. \& Cebollada, A. (2003). Movilidad y transporte. Opciones politicas para la ciudad. Documento de Trabajo, 25. Madrid: Fundación Alternativas.

Miralles, C. (2002). Ciudad y transporte. El binomio imperfecto. Barcelona: Ariel.

Mundó Tejada, J. (2002). El transporte colectivo urbano. Aplicación del enfoque de sistemas para un mejor servicio. Revista Venezolana de Sociología y Antropología, 12(34), 285-302. 
Mundó Tejada, J. (2008). Modelo conceptual del transporte público para Caracas y sus beneficios potenciales. En II Seminario de Movilidad, Experiencias Latinoamericanas: Cómo moverse mejor en Caracas. Caracas, 2-3 de abril de 2008.

Naciones Unidas \& CEPAL (2010). El desarrollo sostenible en América Latina y el Caribe. Tendencias, avances y desafios en materia de consumo y producción sostenibles, minería, transporte, productos quimicos y gestión de residuos. Informe para la decimoctava sesión de la Comisión sobre el Desarrollo Sostenible de las Naciones Unidas. Santiago: Naciones Unidas.

Naciones Unidas. (2010). Objetivos de desarrollo del milenio. Avances en la sostenibilidad ambiental del desarrollo en América Latina y el Caribe. Santiago: Autor.

Nagel, J. (2007). La cola no es gratis. AnálisisVenezuela, 12, 1-4.

Nash, C. (2003). Final Report, with contributions from partner: UNITE (UNIfication of accounts and marginal costs for Transport Efficiency), Final Report for Publication. Leeds: European Commission.

Ocaña, R. V. (2008). Situación del sistema de transporte público de Caracas y acciones para su mejora. En II Seminario de Movilidad, Experiencias Latinoamericanas. Cómo moverse mejor en Caracas. Caracas, 2-3 de abril de 2008.

Ojeda, J. C. (2008). Acciones básicas seguridad vial. En II Seminario de Movilidad, Experiencias Latinoamericanas. Cómo moverse mejor en Caracas. Caracas, 2-3 de abril de 2008.

Paiva, A. (2001). Caracas: en busca de un gobierno metropolitano. EURE. 27(81), 43-59. doi: $10.4067 /$ S0250-71612001008100003

Precedo, A. (1996). Ciudad y desarrollo urbano. Madrid: Síntesis.

Preston, J. \& Rajé, F. (2007). Accessibility, mobility and transport-related social exclusion. Journal of Transport Geography, 15(3), 151-160. doi:10.1016/j.jtrangeo.2006.05.002

Rebotier, J. (2009). La dimensión territorial del riesgo urbano en Caracas: características y alcances. Una propuesta integradora para pensar el riesgo. TRACE, 56, 11-25. Disponible en http:// www.cemca.org.mx/trace/TRACE_56/Rebotier_T56.pdf

Rodrigue, J. P., Comtois, C., \& Slack, B (2006). The geography of transport systems. Londres: Routledge Taylor \& Francis.

Sanz, A. (2010). Transporte, economía, ecología y poder. La economía del transporte desde un enfoque ecointegrador. Ekonomiaz, 73, 148-177.

Sen, A. (1999). Development as Freedom. Nueva York: Alfred A. Knopf. [Ed. cast.: Desarrollo y libertad. Barcelona: Planeta, 2000].

Sucre, F. (1997). La gestión ambiental y la calidad del aire en Caracas. Venezuela Analítica. Ciencia y Tecnología, 18. Revista electrónica, agosto.

Unión Internacional del Transporte Público (UITP). (2003a). Por una mejor movilidad urbana en los países en desarrollo. Problemas, soluciones, realizaciones ejemplares. Bruselas: Autor.

Unión Internacional del Transporte Público (UITP). (2003b). Ticket to the future: 3 stops to sustainable mobility. Bruselas: Autor.

Unión Internacional del Transporte Público (UITP). (2005). Mobility Cities Database. Bruselas: Autor.

Unión Internacional del Transporte Público (UITP). (2007). La lucha contra la exclusión social. El papel del transporte público. FOCUS (mayo), Bruselas. 
United Nations-Habitat [United Nations Human Settlements Programme]. (2007). Enhancing urban safety and security. Londres: Autor.

United Nations-Habitat [United Nations Human Settlements Programme]. (2008). State of the World's Cities 2008/2009. Harmonious cities. Londres: Autor.

Urdaneta. J. A. (2008). Participación en la gestión del transporte público urbano en Venezuela. En XIII Congreso Internacional del CLAD sobre la Reforma del Estado y de la Administración Pública, Buenos Aires, 4-7 de noviembre de 2008.

Vasconcellos, E. (1996). Transporte urbano nos paises en desenvolvimento. São Paulo: Editoras Unidas.

Vasconcellos, E. (2002). Transporte urbano, espaço e equidade. Análise das políticas públicas. São Paulo: Annablume.

Vasconcellos, E. (2005). Urban change, mobility and transport in Sao Paulo: three decades, three cities. Transport Policy, 12, 91-104.

Vasconcellos, E. (2010a). Análisis de la movilidad urbana. Espacio, medio ambiente y equidad. Bogotá: Corporación Andina de Fomento.

Vasconcellos, E. (2010b). El futuro de la movilidad urbana en América Latina. Ciudad de México: Corporación Andina de Fomento.

World Health Organization (WHO). (2010). Global status report on road safety. Ginebra: WHO/ Department of Violence \& Injury Prevention \& Disability (VIP).

Zegras, C. (1998). The costs of transportation in Santiago de Chile. Analysis and policy implications. Transport Policy, 5(1), 9-21. 